\title{
Parâmetros curriculares nacionais para o ensino fundamental: análise de sua proposta para os anos iniciais
}

Jaqueline de Morais Costa

Nilcéia Aparecida Maciel Pinheiro

\section{Resumo}

O presente artigo tem como objetivo discutir sobre as orientações que emanam dos Parâmetros Curriculares Nacionais (PCNs), publicado pelo Ministério da Educação em 1997, analisando as principais premissas apontadas por este documento para a etapa dos anos iniciais do ensino fundamental. Entre suas propostas, os PCNs apontam: os conteúdos desenvolvidos nas esferas conceituais, procedimentais e atitudinais; a concretização de um currículo tratado de forma contextualizada e interdisciplinar; a organização escolar em ciclos; a avaliação tratada como processo formativo e a formação integral do aluno. Mesmo após quinze anos de sua publicação, é possível perceber como os Parâmetros Curriculares Nacionais atendem as necessidades atuais da educação, sendo considerado que as fragilidades ainda presentes nas escolas brasileiras podem ser associadas à dificuldade de concretização de tais propostas.

Palavras-chave: Parâmetros Curriculares Nacionais; Anos Iniciais do Ensino Fundamental; Educação Integral.

\begin{abstract}
This article aims to discuss the guidelines emanating from the National Curriculum Parameters (PCN), published by the Ministry of Education in 1997, examining the key assumptions outlined in this document to the stage of the early years of elementary school. Among its proposals, the NCP point: the contents developed in spheres conceptual, procedural and attitudinal; achieving a curriculum treated contextualized and interdisciplinary; school organization in cycles; treated as assessment and training process, the education of the student . Even after fifteen years of its publication, it is possible to see how the National Curriculum meet the current needs of education, considered that weaknesses still present in Brazilian schools may be associated with difficulty in achieving such proposals.
\end{abstract}

Keywords: National Curriculum Parameters; The First Years of Elementary School; Integral Education. 


\section{Introdução}

Após a reestruturação do sistema educacional brasileiro, apresentado por meio da Lei de Diretrizes e Bases da Educação (LDB) no 9394/96, houve a necessidade de também serem revistos os currículos para então educação básica, anteriormente tratada como primeiro e segundo graus.

Considerando que a LDB agora propunha a flexibilidade, a diversificação e o respeito à regionalidade, foi oportunizado aos sistemas educacionais e às instituições a estes ligadas o princípio da autonomia na organização dos currículos. Todavia, tal liberdade não poderia levar o Brasil a ter propostas de formação tão distintas que não pudessem compor um quadro de competências e habilidades necessárias à formação do estudante em cada uma das etapas de sua escolarização.

Baseado nesses princípios, o Ministério da Educação (MEC) publicou no ano de 1997 os Parâmetros Curriculares Nacionais (PCNs), que englobam em seus diversos volumes orientações para a composição dos currículos do ensino fundamental e do ensino médio. Desta forma, o Estado não elenca de forma fixa e engessada uma lista de conteúdos a serem aprendidos pelos estudantes, mas apresenta os objetivos para cada uma das etapas de formação, as habilidades e competências que precisam ser desenvolvidas pelo aluno e alguns pressupostos de formação, como transversalidade, a interdisciplinaridade, a transdisciplinaridade, a avaliação contínua e a organização escolar por ciclos.

Delimitando o foco da presente discussão, o presente artigo tem como objetivo discutir sobre a proposta dos PCNs para o ensino fundamental. Primeiramente se apresentam os pressupostos desta fase da escolarização e quais os seus principais objetivos de formação. Em um segundo momento, apresentam-se as propostas dos PCNs, trazendo em paralelo um diálogo de pesquisadores sobre os pressupostos apresentados. Por fim, conclui-se que, apesar de completarem quinze anos desde a data de sua publicação, muitas de suas orientações não foram totalmente consolidadas pelos sistemas educacionais.

\section{Anos Iniciais do Ensino Fundamental}

A luta pela redemocratização do Brasil, após o fim do regime militar, teve o início de sua consolidação com a nova Constituição Brasileira sancionada em 1988. A Carta Magna prevê o redimensionamento de vários aspectos de intervenção do Governo e, entre eles, o da educação. Segundo Meksenas (2005), a fim de se concretizarem os preceitos para a educação colocados na Nova Constituição, foi necessário construir um conjunto de leis complementares, as quais deveriam direcionar os rumos dos sistemas educacionais brasileiros. 
Com isso, foi elaborada em 1996 a Lei de Diretrizes e Bases da Educação Brasileira no 9394 (LDB 9394/96) que, entre vários aspectos discutidos, reformula a nomenclatura dos níveis escolares, considerando a educação básica - composta pela educação infantil, ensino fundamental e ensino médio - e o ensino superior (BRASIL, 1996).

O ensino fundamental é colocado no artigo 32 da Lei de Diretrizes e Bases da Educação como única etapa de escolarização obrigatória composta na versão original da LDB por oito anos, modificada posteriormente por meio do Parecer do CNE/CEB ${ }^{1}$ nำ7/2007 para o período de nove anos.

A LDB coloca como objetivos para formação da criança durante o ensino fundamental:

I - o desenvolvimento da capacidade de aprender, tendo como domínios básicos o pleno domínio da leitura, da escrita e do cálculo;

II - a compreensão do ambiente natural e social, do sistema político, da tecnologia, das artes e dos valores que fundamentam a sociedade;

III - o desenvolvimento da capacidade de aprendizagem, tendo em vista a aquisição de conhecimentos e habilidades e a formação de atitudes e valores; IV - o fortalecimento dos vínculos da família, dos laços de solidariedade humana e de tolerância recíproca em que se assenta a vida social (Brasil, 1996, art. 32ㅇ).

Segundo Piletti (2001), o ensino fundamental deve garantir a formação integral do educando e que esta ocorra de forma indissociável à formação do cidadão, construindo as habilidades, tanto para o trabalho como para a continuidade de seus estudos. É possível considerar que esta fase da escolarização pretende garantir ao indivíduo o direito de ingressar na vida social ao adquirir a instrumentalização necessária para uma leitura do mundo que o cerca. Posteriormente, esta leitura proporcionará a ele meios para garantir a sua própria sobrevivência.

Quanto a sua atual organização, o ensino fundamental pode ser visualizado conforme o quadro 1, apresentado abaixo:

\begin{tabular}{|c|c|c|c|c|c|c|c|c|}
\hline \multicolumn{8}{|c|}{ Ensino Fundamental } \\
\hline \multicolumn{8}{|c|}{ Anos Iniciais } & \multicolumn{5}{c|}{ Anos Finais } \\
\hline $1^{\circ}$ ano & $2^{\circ}$ ano & $3^{\circ}$ ano & $4^{\circ}$ ano & $5^{\circ}$ ano & $6^{\circ}$ ano & $7^{\circ}$ ano & $8^{\circ}$ ano & $9^{\circ}$ ano \\
\hline
\end{tabular}

Quadro 1: Organização do Ensino Fundamental

${ }^{1}$ CNE - Conselho Nacional de Educação/ CEB - Câmara de Educação Básica. 
Fonte: Brasil (2004, p. 18)

Um dos principais pontos considerados para o ensino nos anos iniciais é a construção da autonomia e ao mesmo tempo o trabalho coletivo, pois as crianças nesta fase da infância possuem características geralmente individualistas, principalmente durante o primeiro ciclo do ensino fundamental, referente aos três primeiros anos de escolarização. Portanto, a intervenção do professor faz-se necessária à busca do aperfeiçoamento das relações sociais entre aluno-aluno, aluno-professor e aluno-comunidade. Além disso, aponta-se a importância do papel do professor nos anos iniciais, pois será ele quem irá introduzir os primeiros conhecimentos científicos na formação dos alunos (Pais, 2006).

O ingresso da criança no ensino fundamental tem seu momento marcado pela fase de seu desenvolvimento, o qual apresenta características que demonstram ascapacidadescognitiva e motora necessárias para a alfabetização, ilustradas no segmento de texto a seguir:

[...] compreender o mundo, estruturando seu pensamento e fazendo uso de múltiplas linguagens. [...]. Além disso, fazem uso pleno de suas possibilidades de representar o mundo, construindo, a partir de uma lógica própria, explicações mágicas para compreendê-lo (Brasil, 2004, p. 19).

Percebe-se que os anos iniciais da escolarização fundamental configuram um aspecto primordial da formação humana, uma vez que neste momento a criança tomará contato com a cultura socialmente construída de forma sistematizada, em outras palavras, serão, propositalmente, elencados saberes necessários para sua formação, pensando-se na construção de bases suficientes para a compreensão de conhecimentos posteriores. Tudo isso somado configura-se na socialização plena do indivíduo, tornando-o capaz de perceber, compreender e agir na sociedade. Nadal $(2007$, p. 23$)$ reafirma essas considerações ao expor que "o aluno precisa aprender, uma vez que a cidadania pressupõe o domínio de conhecimentos".

Porém, é importante ressaltar que esse processo não está se iniciando em um vazio. Deve-se considerar que essa criança já começou sua formação enquanto indivíduo desde o seu nascimento (Oliveira, 1998), e aprendizados construídos anteriormente por ela jamais poderão ser desconsiderados pela escola. Segundo Nadal (2007, p. 23), é necessário "compreender o aluno como sujeito histórico, ou seja, como alguém que tem a sua identidade construída a partir de um espaço geográfico e de um momento histórico específico".

Logo, torna-se primordial, não somente delinear o que o indivíduo precisa construir, mas também compreender que seu processo de desenvolvimento tanto cognitivo, como emocional, social e físico não está iniciando com seu ingresso na escola. Assim sendo, cabe à escola garantir o progresso desses mesmos aspectos. Explicando melhor, é necessário "[...] considerar a 
especificidade da faixa etária das crianças significa reconhecê-las como cidadãs e, portanto, como possuidoras de direitos [...]" (Brasil, 2004, p. 22).

O direito à escolarização é garantido pela LDB 9394/96 em seu artigo 4으, dado ao reconhecimento da importância da educação escolar na formação do indivíduo. Desse modo, os anos iniciais do ensino fundamental se configuram como uma etapa primordial para a formação do indivíduo em um aspecto amplo a partir do momento em que fornecem a estes conhecimentos essenciais para seu desenvolvimento individual e social.

\section{Parâmetros Curriculares Nacionais: 0 Eixo Norteador para a Organização dos Anos Iniciais do Ensino Fundamental.}

Considerando os aspectos gerais da educação no Brasil, a LDB 9394/96 ofereceu condições para a construção dos Parâmetros Curriculares Nacionais (PCNs), cujo objetivo é garantir um currículo mínimo para a educação básica brasileira, porém, "com propostas inovadoras, como por exemplo, a incorporação da transdisciplinaridade nas práticas pedagógicas" (Meksenas, 2005, p. 103).

Os PCNs formam, assim, as diretrizes para a construção do currículo do sistema educacional brasileiro para os níveis fundamental e médio. Encontram-se organizados da seguinte maneira: Parâmetros Curriculares Nacionais - Ensino Fundamental, publicados em 1997, contêm dez volumes que atendem a denominada $1^{\text {ạ }}$ a $4^{\text {a }}$ séries, condizente com a nomenclatura adotada nos sistemas organizados por ciclos como "Anos Iniciais do Ensino Fundamental" ou "Fundamental I" (um volume de introdução e outros nove contemplando os ensinos de Língua Portuguesa, Matemática, Ciências Naturais, História e Geografia, Arte, Educação Física e Temas

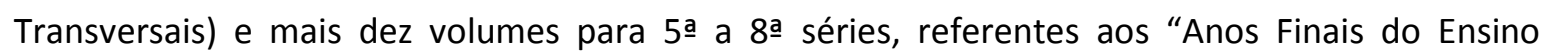
Fundamental" ou "Ensino Fundamental II" (que atendem os mesmos conhecimentos já citados). Há também os Parâmetros para o Ensino Médio, os quais tiveram sua publicação em 1999 e apresentam-se divididos em três áreas do saber: Linguagens, Códigos e suas Tecnologias; Ciências da Natureza, Matemática e suas Tecnologias; Ciências Humanas e suas Tecnologias.

Bittencourt (2004, p. 75) comenta que:

[...] os Parâmetros Curriculares Nacionais surgem no Brasil, na década de noventa, inseridos em um esforço político para organizar propostas curriculares norteadoras das práticas docentes, de modo a consolidar indicativos importantes para a educação brasileira futura.

Apesar de colocados como uma referência à organização do currículo nacional, os PCNs nascem com a proposta de respeito às peculiaridades das diferentes regiões brasileiras. Por isso, a apresentação da estrutura curricular é posta de maneira flexível e, além disso, "eles não se 
impõem como uma diretriz obrigatória: o que se pretende é que ocorram adaptações, por meio do diálogo, entre estes documentos e as práticas já existentes [...]” (Brasil, 1997, p. 29).

$\mathrm{Na}$ redação do texto de apresentação, no volume de introdução, encontra-se uma discussão sobre a situação da educação brasileira ilustrada por dados estatísticos, os quais mostram claramente uma disparidade com relação as suas regiões, como número de alunos e de estabelecimentos de ensino, promoção, repetência e evasão escolar, desempenho dos alunos em avaliações externas e formação dos professores. Posteriormente, os profissionais da educação são convidados a refletirem sobre esses números e a proposta é a busca por uma educação mais igualitária, de maior qualidade e a "formação de cidadãos autônomos, críticos e participativos, capazes de atuar com competência, dignidade e responsabilidade na sociedade em que vivem" (Brasil, 1997, p. 27).

Ao se falar sobre a função dos Parâmetros Curriculares Nacionais, ainda no volume Introdução, é esclarecido que eles:

São uma referência nacional para o ensino fundamental; estabelecem uma meta educacional para a qual devem convergir as ações políticas do Ministério da Educação e do Desporto [...] Têm como função subsidiar a elaboração ou a revisão curricular dos Estados e Municípios, dialogando com as propostas e experiências já existentes, incentivando a discussão pedagógica interna das escolas e a elaboração de projetos educativos, assim como servir de material de reflexão para a prática de professores (Brasil, 1997, p. 29).

Outro ponto contemplado nos PCNs é o quanto a educação escolar deve estar próxima da formação do cidadão. Nogueira $(2001$, p. 35) comenta que o referido documento trata sobre a formação integral do aluno, concebendo:

a capacidade cognitiva como uma capacidade de resolver problemas nas mais diversas situações da vida, utilizando para isto as aquisições da linguagem, matemática, representações espaciais, temporal, gráfica, a utilização do corpo $e$ as expressões da emoção.

Em Santomé (1998) encontra-se que a finalidade da educação escolar, ao construir o currículo, suas bases organizacionais e assumir uma metodologia, é a da formação de cidadãos mais atuantes na resolução das problemáticas que acometem a sua realidade. Para tanto, é na escola que as primeiras práticas cidadãs devem ser vivenciadas, como forma de construção da responsabilidade social em nossos alunos. Com esse enfoque, direciona-se para uma organização curricular baseada na dinâmica emancipadora.

Para que isto aconteça é proposto um ensino mais significativo ao aluno, aplicável à realidade vivida e tratada de maneira interdisciplinar, isto é, construir uma maior relação entre as 
áreas do conhecimento e destas com situações que permeiam o dia-a-dia do educando. Para Nogueira (2001), seguindo os PCNs, o ensino deveria ser tratado de uma maneira inversa à maioria das práticas escolares encontradas hoje; o ideal seria não um conteúdo tratado com fim em si mesmo, mas de maneira relacionada às demais áreas do conhecimento e aos acontecimentos reais que circundam a vida do aluno.

Com isto, é então colocado o trabalho com os conteúdos escolares organizados em três categorias: conteúdos conceituais, procedimentais e atitudinais. Essa categorização remete à compreensão de que os ensinamentos escolares não podem mais ficar única e exclusivamente em torno de transmitir ao aluno apenas informações, mas deve favorecer a este a capacidade de tratar essas informações como instrumentos de interpretação do mundo que o cerca (Freire, 2002).

Assim, os conteúdos conceituais referem-se ao desenvolvimento da capacidade intelectual do aluno e ao reconhecimento das representações de cada área do saber. Segundo Vasconcellos (2005), esses conhecimentos caracterizam a dimensão do "saber" e abrangem aspectos como "conhecimentos de fatos, fenômenos, conceitos, princípios, leis, saberes, ideias, esquemas, informações" (Vasconcellos, 2005, p. 141). Por meio desses conteúdos, o educando recebe informações necessárias para uma melhor compreensão do mundo a sua volta.

Os conteúdos procedimentais apontam o desenvolvimento da capacidade do aluno em realizar ações pautadas nos conceitos, ou seja, é o "saber fazer", envolvendo "tomar decisões e realizar uma série de ações, de forma ordenada e não aleatória, para atingir uma meta" (Pilletti, 2001, p. 91). Os PCNs apontam essa categoria como a construção feita pelo aluno a partir do seu aprendizado. Considera-se ainda que, ao se "ensinar procedimentos também se ensina um certo modo de pensar e produzir conhecimento" (Brasil, 1997, p. 52).

Por fim, considerando que a escola tem como finalidade a integração social dos mais jovens a uma cultura já existente, os conteúdos atitudinais envolvem a formação de valores e promovem atitudes mais reflexivas. Significa a "disposição do sujeito; modos de agir, sentir, se posicionar" (Vasconcellos, 2005, p. 141). Assim, ocorre a integração da criança e do jovem ao meio social por compreender as atitudes que são esperadas em um cidadão.

Essa categorização dos conteúdos vem promover a reflexão de que os conhecimentos escolares vão além de meras informações, mas também se constituem de momentos de construção de habilidades, valores, atitudes que formarão o ser social de forma integral.

É importante salientar que essas categorias não são tratadas de forma individualizada. A garantia de se construir o conhecimento enquanto processo socializador advém das práticas escolares para a formação integral do aluno. Com isso, o papel do professor é "apresentar os conteúdos e atividades de aprendizagem de forma que os alunos compreendam o porquê e o 
para que do que aprendem e, assim, desenvolvam expectativas positivas em relação à aprendizagem e se sintam motivados [...]" (Brasil, 1997, p. 48).

Assim, segundo Bittencourt (2004, p. 79), é promovida uma nova reflexão acerca do que envolve a educação:

As diversas soluções apontadas nos PCN, isto é, a contextualização, a transversalidade, ou a abordagem temática, apontam todas na direção de uma necessária revisão de uma escola que, mal ou bem, conseguiu se manter alheia ao dinamismo da nossa vida social.

Verifica-se, portanto, que há uma busca incessante em atribuir maior relação entre os conteúdos disciplinares, e desses com a vivência dos envolvidos no ato educacional. Com isso, construir práticas escolares mais relevantes se torna o grande desafio da educação do século XXI (Santomé, 1998). Para isso, a orientação das práticas escolares precisa enfatizar mais em construir, no aluno, condições necessárias para que este possa desenvolver estratégias de leitura e decodificação de situações relacionadas à sociedade e ao meio-ambiente em que vive. Isso remete ao conceito de ensino contextualizado, do qual se retira o foco do conceito para se destacar a importância deste para a compreensão da realidade.

O autor Gasparin (2007) atribui à expressão "prática social inicial” quando o professor contextualiza os conteúdos presentes no currículo. Todos os assuntos devem ser tratados de forma a levar o aluno a problematizar a realidade em que vive, a fim de fazer a sua própria construção, colocada pelo autor como "prática social final". Esse movimento de leitura e releitura da realidade propicia uma formação mais crítica ao aluno, tornando-o capaz de compreender e interferir com mais propriedade no meio social. Na redação dos PCNs encontra-se claramente uma alusão ao ensino contextualizado:

O professor, considerando a multiplicidade de conhecimentos em jogo nas diferentes situações, pode tomar decisões a respeito de suas intervenções e da maneira como tratará os temas, de forma a propiciar aos alunos uma abordagem mais significativa e contextualizada (Brasil, 1997, p. 44).

Principalmente nos anos iniciais da escolarização, um ensino que faça parte da vida da criança contribuirá diretamente para a compreensão do que se está sendo ensinado:

A contextualização dessas crianças contribui para uma compreensão que abre caminhos na direção de uma aprendizagem inclusiva. Pelo fato de viverem numa sociedade cuja cultura dominante é a letrada, desde que nascem as crianças constroem conhecimentos prévios sobre o sistema de representação e o significado da leitura e da escrita. Esses conhecimentos passam inclusive pela 
incorporação da valorização social que tem a aquisição do ler e escrever (Brasil, 2004, p. 21).

Nesta perspectiva, a escola precisa considerar a dinâmica da sociedade em que o aluno está inserido, a qual hoje marca uma era voltada à facilidade de acesso à informação. Em vista disso, trazer à tona temas interessantes aos alunos (os quais são parte dessa sociedade) é dinamizar os conhecimentos escolares, é dar-Ihes significados inerentes a cada época vivenciada. Araújo (2003) alerta para a necessidade de uma visão de educação que rompa com a fragmentação e descontextualização do conhecimento escolar.

O docente, ao contextualizar as temáticas trabalhadas na escola, poderá proporcionar ao educando um aprendizado com maior significado. Isso ocorre pela compreensão dos conteúdos atrelada a situações vividas no cotidiano do aluno.

Ao passo em que se contextualiza o saber, emana-se a necessidade de tratá-lo de forma interdisciplinar, uma vez que situações reais dificilmente ocorrerão de forma compartimentada como ocorre na apresentação das matrizes curriculares, isto é, dividido em disciplinas. Contudo ainda está saliente a dificuldade em se trabalhar com o currículo de forma mais integrada, istoadvindoda consideração de que o professor é fruto de uma herança cultural transmitida e por isso, socialmente aceita (SANTOMÉ, 1998). Na busca de romper com um ensino tratado de maneira excessivamente especializada é que surge a discussão em torno da interdisciplinaridade.

Considerar o ensino com enfoque interdisciplinar não se limita apenas a questões metodológicas que atenderão particularmente a escola. Essa postura irá viabilizar também, novas formas de intervenção dos indivíduos no meio social, a fim de corresponder às novas exigências que nela se configuram:

Também é preciso frisar que apostar na interdisciplinaridade significa defender um novo tipo de pessoa, mais aberta, flexível, solidária, democrática e crítica. o mundo atual precisa de pessoas com uma formação cada vez mais polivalente para enfrentar uma sociedade na qual a palavra mudança é um dos vocábulos mais frequentes e onde o futuro tem um grau de imprevisibilidade como nunca em outra época da história da humanidade (Santomé, 1998, p. 45).

Ainda segundo Santomé (1998), interdisciplinaridade pode ser conceituada como uma abordagem metodológica de trabalho em que os conhecimentos escolares são estudados e ensinados tendo como referência situações e problemáticas reais. Não há uma linha única que delimite como se conduzir os conteúdos escolares de forma interdisciplinar, porém, geralmente alguns requisitos têmse mostrado presentes nesta forma de abordagem, tais como: definição de um problema a ser investigado; determinação dos conhecimentos que serão necessários para a resolução do problema; delimitação de um marco integrador para esses conhecimentos 
envolvidos; especificação dos estudos necessários; reunião destes conhecimentos em torno da busca da resolução do problema; resolução de conflitos que podem surgir quando se alinham várias áreas do conhecimento; garantia à comunicação do que já foi descoberto; avaliação do trabalho constantemente; integração das descobertas individuais; ratificação quando necessário às respostas; decisão sobre as tarefas.

O enfoque interdisciplinar é dividido em algumas modalidades. Entre elas encontra-se o de multidisciplinaridade, o qual considera o ensino por meio de uma ligação entre as disciplinas, porém, sem uma integração; há uma separação visivelmente delimitada entre as áreas do saber, mesmo em um estudo comum (Santomé, 1998). Nogueira (2001) define esse termo como sendo a integração de vários conteúdos dentro de uma mesma disciplina, não havendo relação com outras áreas do conhecimento.

Já a pluridisciplinaridade é explicada por Santomé (1998) como a união de disciplinas cujo foco de estudo é comum ou muito próximo. Trabalha-se em torno de um mesmo tema, porém, sem integração, pois cada professor dará o seu foco prioritário para o assunto (Araújo, 2003).

A disciplinaridade cruzada ocorre quando uma disciplina faz uso de saberes de outras áreas para explicar uma situação (Santomé, 1998).

A interdisciplinaridade, propriamente dita, ocorre quando há a integração de diferentes disciplinas em um trabalho coordenado, saindo da compartimentalização dos conteúdos para uma unificação (Nogueira, 2001). Santomé (1998) salienta que essa interligação das diferentes áreas do saber será em torno da resolução de um problema, ocorrendo com isso uma interdependência entre os diferentes aspectos de se responder ao problema pesquisado.

A última modalidade de interdisciplinaridade é a transdisciplinaridade que, segundo Araújo (2003), marca o momento em que desaparecem os limites entre as disciplinas. Os conteúdos são tratados de forma integrada como um conhecimento único, remetido à busca de soluções para problemas reais (Santomé, 1998).

Dentro do contexto dos anos iniciais do ensino fundamental, a própria organização escolar beneficia o desenvolvimento de tais condições. Considerando que, especialmente na rede pública, as classes são conduzidas por professores unidocentes, é possível dentro de um planejamento global, determinar habilidades e competências a serem desenvolvidas pelos alunos dentro de um determinado tempo, e, partindo dessas bases, desenvolver o trabalho educativo em torno de temáticas interessantes à fase da infância vivida pelos educandos. Assuntos como animais, brincadeiras, personagens da literatura infantil são propícios para a motivação de conteúdos escolares. Não é necessário separar o momento de explicações e exercícios de português, matemática, ciências ou artes, pois todos estes poderão ser desenvolvidos em uma única atividade de estudo, planejamento e ação das crianças com mediação do professor. 
Além disso, a importância em se trabalhar de forma inter ou transdisciplinar é a formação de pessoas mais autônomas e com capacidade de leitura da realidade, pois na escola aprenderam não apenas os conteúdos, mas sua manifestação em situações reais.

As propostas apresentadas pelos PCNs vêm em consonância com uma visão de ensino que atenda mais precisamente as necessidades do educando em sua vida social. Além de preocuparse com o trato dos conteúdos escolares, também sugerem a organização escolar em forma de ciclos em lugar do tradicional sistema seriado, colocada como "tentativa de superar a segmentação excessiva produzida pelo regime seriado e de buscar princípios de ordenação que possibilitem maior integração do conhecimento" (Brasil, 1997, p. 42). Segundo o mesmo documento, as séries anuais devem dar lugar a ciclos de dois anos de duração. ${ }^{1}$ Com essa medida se objetiva proporcionar a superação da reprovação desnecessária, principalmente no primeiro ano do ensino fundamental e oportunizar uma alfabetização mais efetiva.

Um sistema educacional baseado em ciclos não visa apenas à alteração na organização escolar, mas também na maneira de se pensar o desenvolvimento da aprendizagem, a avaliação e a aprovação/reprovação (Miranda, 2005).

Para Soares (2002, p. 89), "os ciclos introduzem na organização escolar uma temporalidade que leva em conta o caráter processual da construção do conhecimento e as especificidades do momento de formação do educando". Segundo Rosa Neto (2005, p. 43), devese considerar que "as crianças não amadurecem do mesmo modo. Há diferenças de ritmos, percurso, de quantidade, de qualidade, e isso depende de diversos fatores". Com isso, percebe-se que o sistema educacional baseado em ciclos respeita mais facilmente o ritmo de desenvolvimento do aluno que o sistema seriado, pois é dado um período de trabalho para que o professor auxilie o educando no seu processo de desenvolvimento, o qual não se encerra abruptamente com o final do ano letivo. Para Vasconcellos (2006), a lógica organizacional dos ciclos rompe a visão de ensino classificatório imposto pelo sistema seriado baseado em notas, uma vez que é priorizado o processo de desenvolvimento, considerando o que já foi construído e as possibilidades que o aluno poderá atingir por meio da mediação do professor.

Além disso, o ensino fundamental organizado por ciclos centra-se não "mais nos conteúdos disciplinares, mas na formação dos educandos, tendo em vista a multiplicidade de dimensões que compõe esse processo: dimensões de natureza afetiva, emocional, cultural, simbólica, intelectual, ética, estética [...]" (Soares, 2002, p. 91). Sobre esse aspecto, o texto dos Parâmetros salienta que:

\footnotetext{
${ }^{1}$ Com o decreto $\mathrm{n}^{\mathrm{o}}$ 11.274/06 que altera o ensino fundamental para nove anos de duração, há também mudança na organização da educação por ciclos. Sendo assim, o primeiro ciclo, correspondente ao momento de alfabetização, teria duração de três anos e os demais ciclos dois anos de duração. Com isso, os anos iniciais do ensino fundamental passam a conter cinco anos de escolarização.
} 
Os conhecimentos adquiridos na escola passam por um processo de construção e reconstrução contínua e não por etapas fixadas e definidas no tempo. As aprendizagens não se processam como subida de degraus regulares, mas como avanços de diferentes magnitudes (Brasil, 1997, p. 43).

Assim, o educando tem respeitadas suas construções e reconstruções, as quais permeiam os caminhos da ampliação de sua aprendizagem. Rompe-se com a visão errônea de ensino de forma linear, em que se força uma temporalidade muitas vezes incompatível com o desenvolvimento dos alunos.

A proposta do sistema de ensino organizado por ciclos vem ao encontro de uma perspectiva de ensino centrada no processo ensino-aprendizagem, pois proporciona ao aluno um tempo maior para adquirir os conhecimentos necessários para a progressão de seus estudos, e ao professor uma maior flexibilidade para desenvolver o seu trabalho. Segundo Vasconcellos (2006), há um compromisso mais acentuado por parte da escola na promoção do desenvolvimento máximo das potencialidades da criança.

Para a concretização desta proposta, torna-se primordial um planejamento integrado entre os docentes, pedagogos e gestores escolares. O registro contínuo do desenvolvimento do aluno, aliado a uma análise reflexiva do docente, assessorado pelo pedagogo, permeará um plano de ação para o resgate de alunos que apresentam alguma dificuldade em seu processo de aprendizagem. Assim, é necessário romper com a visão do ensino massificado, organizando os momentos da aula com atividades gerais para toda classe e outros mais individualizados.

Diante dessa visão acerca da organização do sistema escolar, também um novo enfoque precisa ser dado à avaliação, a qual deverá mudar seu foco de instrumento de aprovação/reprovação e passar a assumir um caráter diagnóstico da aprendizagem do aluno. Todos os esforços para construção de uma educação interdisciplinar, contextualizada e que respeite o desenvolvimento individual da criança seriam inválidos se a concepção de avaliação ainda estiver atrelada a práticas tradicionais de ensino, pois "planejamento e avaliação são atos que estão a serviço da construção de resultados satisfatórios" (Luckesi, 2005, p. 165).

Segundo Cordeiro (2007), o sistema de avaliação deverá estar necessariamente atrelado à concepção pedagógica adotada. Assim, é defendido pelos PCNs que, a partir dos dados colhidos em diversos instrumentos avaliativos (observação, atividades, avaliações formais), o professor seja levado a refletir sobre a sua prática para rever se seus objetivos estão sendo alcançados. Em outras palavras, a avaliação "é compreendida como um conjunto de atuações que tem a função de alimentar, sustentar e orientar a intervenção pedagógica" (Brasil, 1997, p. 55). Dessa maneira, a avaliação estará a serviço de um objetivo maior, constituindo-se em um valioso instrumento de direcionamento da tomada de decisões (Luckesi, 2005). 
Percebe-se que a avaliação não se configura como a finalização do processo ensinoaprendizagem, mas sim como um meio de retroalimentação desta dinâmica compreendida de forma cíclica e não linear, conforme pode ser visualizada na figura 1:

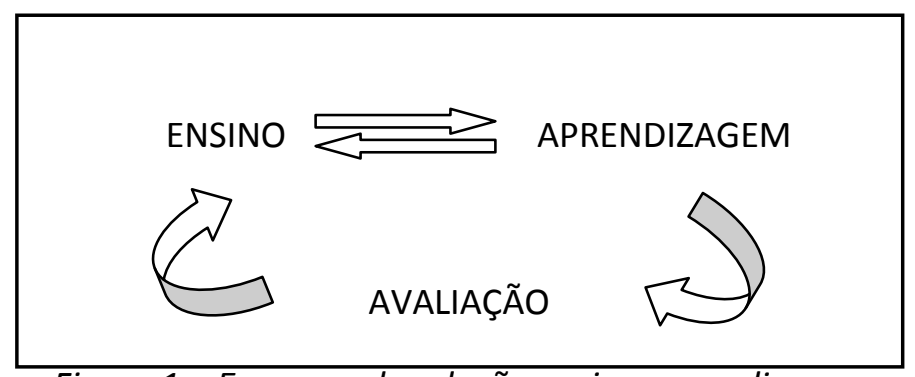

Figura 1 - Esquema da relação ensino-aprendizagem-avaliação

Fonte: Autora

Pode-se concluir que os PCNs abordam uma concepção de ensino-aprendizagem em que se colocam como pontos importantes: a contextualização, como forma de atribuir maior significação ao que se está aprendendo na escola; a interdisciplinaridade, ao se relacionar as áreas do saber em um movimento próximo aos acontecimentos da realidade; respeito ao ritmo de desenvolvimento do aluno, ao considerar a organização dos sistemas escolares por ciclos; avaliação como processo e não como produto final do processo ensino-aprendizagem.

Diante das considerações apresentadas, é possível refletir que o ato de ensinar envolve várias dimensões, indo além de apenas apresentar conceitos aos alunos. Assim, cabe a cada profissional da educação repensar o que sua prática pretende alcançar e, por meio dela, que tipo de cidadãos pretende-se formar. Percebe-se então que promover um ensino que atenda às necessidades sociais é primordial para o crescimento e desenvolvimento da própria sociedade.

\section{Considerações Finais}

As propostas de formação expostas nos PCNs buscam a formação do aluno de uma maneira integral, pois são consideradas as premissas do saber, do fazer e do ser. Mesmo após quinze anos de sua publicação, as propostas expostas nos parâmetros compreendem orientações para organização dos currículos de ensino fundamental e médio respeitando as necessidades de formação da escola atual, pois não elencam uma lista de conteúdos estanques, mas orientam para objetivos a serem alcançados durante cada etapa da escolarização. 
Os preceitos descritos nos PCNs orientam para um ensino tratado de forma contextualizada e interdisciplinar, pois valoriza o envolvimento do aluno com o saber. Tais concepções ainda têm sido encaradas como uma dificuldade enfrentada pelas escolas, pois a própria organização curricular, na maioria das escolas, tem sido apresentada de forma compartimentada, definindo em cada uma das áreas o que deve ser trabalhado em cada ano escolar do aluno, ficando ao encargo do professor contextualizar e promover a interdisciplinaridade, esta, ainda, com o agravante de depender de um trabalho coeso de equipe.

Outra proposta discutida foi sobre a avaliação entendida como processo, ou seja, orienta para "o avaliar" de maneira diagnóstica, formativa e processual. Contudo, a escola enfrenta uma cultura instaurada na sociedade que exige o aprendizado convertido em números, além de provas padronizadas que os alunos necessitam fazer, estando ou não em condições de realizá-las.

Por fim, a discussão sobre a educação em ciclos, considerando o respeito ao ritmo de desenvolvimento do aluno. Porém, infelizmente muitas experiências de implantação tiveram conflitos na interpretação da proposta, confundindo-se progressão continuada com aprovação incondicional. $O$ resultado é o grande número de alunos ingressando nos anos finais do ensino fundamental e até mesmo no ensino médio sem estarem plenamente alfabetizados.

Diante das críticas apresentadas acima, este trabalho pretendeu resgatar as orientações para o currículo da escola básica brasileira presentes nos PCNs, abrindo cada uma de suas proposições em diálogo com autores de cada uma das temáticas. Diante do quadro de fragilidade na qualidade da educação brasileira, compreende-se que não são as propostas frágeis, mas sim a sua compreensão e ação no cotidiano da escola, tema este que merece uma extensa discussão.

Com isso, pretende-se contribuir para a formação inicial e continuada de professores de ensino fundamental e médio na reflexão sobre a organização e orientação dos currículos.

\section{Referências}

ARAÚJO, Ulisses Ferreira. Temas transversais e a estratégia de projetos. São Paulo: Moderna, 2003, $108 \mathrm{p}$.

BITTENCOURT, Jane. Sentidos da integração curricular e o ensino de matemática nos Parâmetros Curriculares Nacionais. Zetetiké. Campinas, v.12, n. 22, p.71 -88, jul/dez. 2004.

BRASIL. Lei de Diretrizes e Bases da Educação Nacional no 9394/96. Brasília, 1996.

. Ministério da Educação. Secretaria de Educação Fundamental. Parâmetros curriculares nacionais: ensino fundamental - introdução. Rio de Janeiro: DP\&A, 1997. 
Secretaria de Educação Básica. Ensino fundamental de nove anos: orientações

gerais. Brasília, $2004 . \quad$ Disponível em:

<http://portal.mec.gov.br/index.php?option=com_content\&view=article\&id=12379:ensino-

fundamental-de-nove-anos-publicacoes\&catid=313:ensino-fundamental-de-

noveanos\&ltemid=627>. Acesso em 27 jul. 2010.

CORDEIRO, Jaime. Didática. São Paulo: Contexto, 2007, 189 p.

FREIRE, Paulo. Pedagogia da autonomia: saberes necessários à prática educativa. 25. ed. São Paulo: Paz e Terra, 2002, 165 p.

GASPARIN, João Luiz. Uma didática para a pedagogia histórico-crítica. 4. ed. São Paulo: Autores Associados, 2007, $191 \mathrm{p}$.

LUCKESI, Cipriano C. Avaliação da aprendizagem escolar. 16. ed. São Paulo: Cortez, 2005, 180 p.

MEKSENAS, Paulo. Sociologia da educação: introdução ao estudo da escola no processo de transformação social. São Paulo: Loyola, 2005, 109 p.

MIRANDA, Marília Gouvea de. Sobre tempos e espaços da escola: do princípio do conhecimento ao princípio da socialidade. Educação \& Sociedade, Campinas, v. 26, n. 91, p. 639-651, maio/ago. 2005. Disponível em: <http://www.scielo.br/pdf/es/v26n91/a17v2691.pdf>. Acesso em 04 jul. 2010.

NADAL, Beatriz Gomes (org). Práticas pedagógicas nos anos iniciais:concepção e ação. Ponta Grossa: Editora UEPG, 2007, 182 p.

NOGUEIRA, Nilbo Ribeiro. Pedagogia dos projetos: uma jornada interdisciplinar rumo ao desenvolvimento das múltiplas inteligências. São Paulo: Érica, 2001, 196 p.

OLIVEIRA, Persio S. Introdução à sociologia da educação. 3. ed. São Paulo:Ática, 1998, 184 p.

PAIS, Luiz Fernando. Ensinar e aprender matemática. Belo Horizonte: Autêntica, 2006.

PILETTI, Nelson. Estrutura e funcionamento do ensino fundamental. 26. ed. São Paulo: Ática, 2001, $232 \mathrm{p}$.

ROSA NETO, Ernesto. Didática da matemática. 11. ed. São Paulo: Ática, 2005, 224 p.

SANTOMÉ, Jurjo Torres. Globalização e interdisciplinaridade: o currículo integrado. Tradução: Cláudia Schilling. Porto Alegre: Artes Médicas do Sul, 1998, 275 p.

SOARES, Cláudia Caldeira. Reinventando a escola: os ciclos de formação na escola plural. São Paulo: Annablume, 2002, 180 p.

VASCONCELLOS, Celso dos Santos. Planejamento: projeto de ensino-aprendizagem e projeto político-pedagógico. 14. ed. São Paulo: Libertad Editora, 2005, 205 p. 
. Projeto de ensino-aprendizagem e projeto político-pedagógico: elementos metodológicos para elaboração e realização. 13. ed. São Paulo: Libertad Editora, 2006.

Jaqueline de Morais Costa Mestre em Ensino de Ciência e Tecnologia pela Universidade Tecnológica Federal do Paraná. Especialista em Psicopedagogia pelo Instituto de Estudos e PósGraduação - ESAP. Possui graduação em Licenciatura em Pedagogia pela Universidade Estadual de Ponta Grossa (2005). Atualmente é Coordenadora Geral de Gestão Acadêmica do Centro de Ensino Superior de Campos Gerais. Tem experiência na área de Educação, com ênfase em Ensino Superior, atuando principalmente nos seguintes temas: formação de professores, matemática para anos iniciais do ensino fundamental, professor-pesquisador.

Nilcéia Aparecida Maciel Pinheiro Doutora em Educação Científica e Tecnológica pela Universidade Federal de Santa Catarina (2005). Atualmente é professora do Departamento de Matemática da Universidade Tecnológica Federal do Paraná, atuando nas seguintes áreas: 1) Álgebra Linear e Geometria Analítica, nos cursos de Engenharia Mecânica e de Produção;2) Ensino de Matemática e Educação Científica e Tecnológica, junto ao Programa de Doutorado e Mestrado Profissional em Ensino de Ciência e Tecnologia do qual foi coordenadora de 2007-2009. Faz parte do corpo editorial da RBECT (Revista Brasileira de Ensino de Ciência e Tecnologia) da UTFPR. 